\title{
Comparison and choice: Relations between similarity processes and decision processes
}

\author{
DOUGLAS L. MEDIN \\ Northwestern University, Evanston, Illinois \\ ROBERT L. GOLDSTONE \\ Indiana University, Bloomington, Indiana \\ and \\ ARTHUR B. MARKMAN \\ Columbia University, New York, New York
}

\begin{abstract}
Research and theory in decision making and in similarity judgment have developed along parallel paths. We review and analyze phenomena in both domains that suggest that similarity processing and decision making share important correspondences. The parallels are explored at the level of empirical generalizations and underlying processing principles. Important component processes that are shared by similarity judgments and decision making include generation of alternatives, recruitment of reference points, dynamic weighting of aspects, creation of new descriptors, development of correspondences between items, and justification of judgment.
\end{abstract}

\section{INTRODUCTION}

"My problem is that I have been persecuted by an integer. For seven years this number has followed me around, has intruded in my most private data, and has assaulted me from the pages of our most public journals" (G. A. Miller, 1956, p. 81). So begins George Miller's classic paper on the magic number seven. Miller was intrigued by the observation that both immediate memory and absolute judgments appear to have the same capacity limitation (i.e., seven, plus or minus two, chunks of information). We, too, have been drawn to a parallel by what initially seemed to be coincidence but now forms a pattern of correspondences that we find difficult to dismiss. The domains in question are those of decision making and similarity judgments. So enamored are we of the correspondences that we have come to entertain the idea that decision making entails a similarity judgment. But we will begin with the more modest goal of convincing the reader that bringing these two domains of discourse together is even a good idea.

Preparation of this article was supported by National Science Foundation Grants 92-11277 and 91-10245. We thank Lance Rips, Evan Heit, Jim Sherman, Edward Wisniewski, Dedre Gentner, Reid Hastie, two anonymous reviewers, and especially Hal Arkes for valuable advice, comments, and suggestions. The research described in this article conforms to the American Psychological Association ethical standards for research involving human participants. Correspondence concerning this article should be addressed to D. L. Medin, Psychology Department, Northwestern University, 2029 Sheridan Road, Evanston, IL 60208-2710 (e-mail: medin@nwu.edu).
To avoid later confusion, we need to insert some points and disclaimers. There are some pretty obvious senses in which similarity and decision making are related. It is trivially true that judging which of two objects is more like a third involves a decision; and it has long been known (e.g., Restle, 1961) that the similarity of alternatives affects choice. Our focus, however, is on the processing side of similarity, and we will treat similarity (comparison) as more like a verb than a noun. The fact that the similarity of alternatives influences decisions provides a clue to comparison processes, and it is these processes that are of interest.

Finally, we are agnostic with respect to whether correspondences between similarity and decision making are unique to these domains. We believe that the parallels between these domains are worthy of investigation, even if other domains also exhibit similar correspondences. In fact, if the underlying common processes that we suggest are also shared by other aspects of cognition, such as attention and memory, our analysis will have additional import. Given the fundamental nature of similarity processes and decision processes, it would not be surprising if their shared aspects proved to be general properties of cognition.

The process of categorization merits special consideration as potentially having important properties in common with similarity judgments and decision making. This is hardly surprising, given that many models for categorization are founded on similarity (for a review, see Goldstone, 1994a), and that several models of decision making are based on categorization (e.g., Kah- 
neman \& D. T. Miller, 1986). Many of our specific proposals for common processes, such as dynamic weighting of properties, generation of new properties, and judgment justification, have also been recently developed in the categorization field (Murphy \& Medin, 1985).

It is not immediately obvious that similarity judgments and decision making have much in common. Furthermore, a quick review of typical paradigms from these two areas suggests further differences. Similarity judgments often involve either comparing two entities or judging which of a set of alternatives is most similar to some target or standard. Decision-making studies are frequently concerned with choices between options, where the outcome associated with an option may have some uncertainty associated with it. Three differences in these paradigms immediately suggest themselves: (1) There is no standard or target in decision-making studies; (2) similarity judgment seems to be importantly a function of shared or common properties, but in decision making, properties that options share may be irrelevant to the choice; and (3) there is no obvious ana$\log$ in similarity of the probability dimension in risky choice.

Are the above differences fatal to any deep correspondences between similarity judgments and decision making? For the moment, we offer three counterarguments; later on, we defend them. First of all, understanding the meaning or significance of the properties or aspects associated with a decision implicitly presupposes that some standard or ideal is used to determine their valence and magnitude. We will argue that decision tasks involve a standard that is implicit, or possibly explicit, and prestored, or possibly constructed. In doing so, we also address the issue of the role of common or shared properties. Given some standard, shared or common properties may arise either from comparing alternatives with each other or from comparing alternatives with the standard. Thus, for the second proposed difference, it remains to be seen whether the effects of shared properties on decision making and on similarity judgments are comparable. As for the third difference, for the moment, we will treat probability simply as another dimension along which choices may vary in similarity.

We will argue, further, that the correspondences between similarity judgments and decision making are deep and provocative. Our review and analysis will describe the parallel course of development of these domains, building bridges between domains that have hitherto remained largely independent. Along the way, we will also suggest a number of new possible correspondences.

Early research in both similarity judgments and decision making focused on the idea that subjects converted stimuli into some kind of "common currency," such as utility in the case of decision making (e.g., Luce, 1959), or psychological distance in the case of similarity judgments (e.g., Shepard, 1962a, 1962b). In both areas, behavioral research soon demonstrated that a commoncurrency theory was limited in its ability to describe many phenomena. This research led to calls for the development of theories of the processes involved in making decisions and similarity comparisons, rather than settling for descriptive theories of the choices and judgments themselves (e.g., Tversky, 1972, 1977). We believe that this shared evolution is a function of more profound similarities between the domains.

In the next section, we focus on parallel phenomena in each domain. There are several related strategies for carrying out this analysis. Certain phenomena may be common to both domains but more prominent and easier to analyze in one than in the other. If a phenomenon from one domain has not been studied in the other, the opportunity exists to examine the generality of the associated explanatory mechanisms. Even where phenomena seem to mismatch, closer analyses may reveal deeper relationships or fundamental differences. Finally, comparing and contrasting similarity and choice may serve to highlight mechanisms that would not be salient in either domain considered by itself.

In this paper, we first lay out a series of correspondences between similarity and decision making, and then examine the degree to which these parallels suggest that decision making and similarity judgments involve common processes. Finally, we speculate on the degree to which similarity judgments and decision making may be viewed as two manifestations of the same process.

\section{PARALLEL PHENOMENA}

It will be useful to imagine some generic choice context to motivate our discussion. Consider a situation in which there are three candidates for a teaching position and the decision must be made as to who to interview first (resources are limited, so it is not feasible to interview all three) on the basis of their résumés. First of all, one would need to determine the types of informationsuch as teaching experience and amount of educationthat are relevant to this decision. The résumés would presumably provide specific information or values on these dimensions, and they may even serve to suggest relevant dimensions. Next, the candidates would be compared along these relevant dimensions. Of course, the résumés may not be perfectly comparable, as one may list information (e.g., hobbies, teaching ratings) not included in others. This information must then be integrated in some form to arrive at a decision. To modify the context in the direction of similarity judgments, imagine that the candidates are being compared with some previous teacher, and that the question concerns which of the three candidates is most similar to that teacher.

Of course, if one résumé were outstanding and the others mediocre, the decision would be easy. In many choice contexts, however, one faces tradeoffs across relevant dimensions; one candidate, for example, may have more education but less experience than another. One might think that one should simply weight dimensions according to their importance and select the candidate whose (weighted) overall impression is the highest. There 
is abundant evidence, however, that the weights assigned to dimensions depend importantly on the context and the set of candidates under consideration. We begin our analysis with factors or processes associated with weighting of dimensions in both similarity and choice.

\section{Weighting}

A number of distinct subprocesses have been identified that influence or determine the weights associated with features or dimensions. Cumulatively, these subprocesses suggest that preferences (including similarity judgments) are not simply prestored and retrieved but, rather, are at least partially constructed in the choice context.

\section{S-R Compatibility, Preference Reversals, and Framing}

It is now well established that different measures of preference may disagree with one another. For example, Lichtenstein and Slovic (1973) gave people a choice between bets that involved a high probability of winning a relatively small number of chips (e.g., an $11 / 12$ chance of wining 12 chips, a $1 / 12$ chance of losing 24 chips) or a low probability of winning a larger number of chips (e.g., a $2 / 12$ chance of winning 79 chips, a 10/12 chance of losing 5 chips); the chips could be exchanged for money. They found that, generally, people were roughly indifferent between these two bets but placed a higher selling price on the second bet than they did on the first, regardless of whether they chose the first or the second. These preference reversals are robust, despite their incompatibility with rational choice (e.g., Grether \& Plott, 1979). Tversky, Sattath, and Slovic (1988) have offered an account of these results in terms of a compatibility principle. Their idea is that the weight given to a dimension depends on how compatible it is with the judgmentresponse scale that is being used to assess preference. Asking people to assign a dollar value to a bet favors attention to the amount of money associated with a bet. Tversky et al. provided a number of demonstrations that the weight of a choice dimension is enhanced when it is compatible with the assessment dimension.

Goldstone (1993) obtained an analog of the compatibility effect in a numerosity estimation task. When subjects were shown the two displays in Figure 1 and asked to select the display with a greater percentage of white squares, they had a tendency to select the display on the right. Surprisingly, another group of subjects had a tendency to select the right display as possessing a greater percentage of black squares. Other experiments showed that this intersubject inconsistency is due to a selective weighting of display regions that contain a high concentration of features that are mentioned in the instructions as the basis for the response. For example, if subjects are instructed to choose the display that contains more white squares, they are highly influenced by squares that come from regions with many white squares. Thus, the scene with clusters of black and white squares may appear to

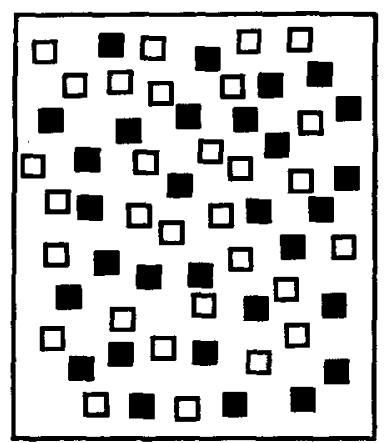

Distributed Display

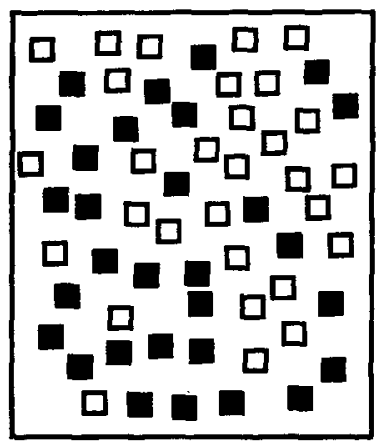

Clustered Display
Figure 1. Stimuli used by Goldstone (1993). There is a tendency for subjects to select the display with clustered regions of black and white squares as possessing a greater percentage of both black and white squares.

contain a greater percentage of both black and white squares, depending on what features are emphasized by the instructions.

There are corresponding compatibility effects in similarity. One parallel derives from Tversky's (1977) contrast model, which assumes that similarity is a weighted function of matching (i.e., common) and mismatching features. Tversky suggested that, compared with similarity judgments, difference or dissimilarity judgments give relatively less weight to common features and more weight to distinctive features. He tested this idea using pairs of stimuli in which one pair had more features (both common and distinctive) than the other (that is, people knew more about one pair than about the other). An example from Tversky involves the pairs \{East Germany, West Germany\} and \{Ceylon, Nepal\}. Tversky found that $67 \%$ of participants rated the two Germanys as more similar than Ceylon and Nepal, while $70 \%$ of a second group rated the two Germanys as more different. This finding is consistent with the suggestion that relative to similarity judgments, difference judgments preferentially weight mismatching features.

In a similar study, Shafir (1992) set up a choice situation in which parents were competing for custody of a child. One parent had both more positive and more negative qualities than the other. One group of participants was asked which parent should be awarded custody, and a second group was asked which parent should not be awarded custody. To a reliable extent, both groups selected the same parent-namely, the one with more positive and negative qualities (see Shafir, 1993, for other examples and further discussion).

\section{Value-Specific Weighting and the Max Principle}

Another finding common to both choice and similarity is that the weight attached to a dimension is not necessarily independent of its value and the overall context. Goldstone, Medin, and Gentner (1991) found violations of independence in similarity judgments in their studies evaluating the relative contributions of attributes (one- 
place predicates, such as "white") and relations (two- or more-place predicates, such as "white triangle above red circle") to similarity judgments. They found that the impact of an added feature on similarity was heightened when the compared objects had other matching features of a similar type (e.g., an attributional match received more weight when the objects were attributionally similar, but a relational match was relatively more important when the objects were relationally similar). They referred to this as a max principle - that is, whichever aspect of similarity maximizes similarity receives more weight.

Rubinstein (1988) has suggested that a similaritybased process that leads to violations of independence can account for the "common-ratio" effect in choice behavior. For example, consider the following choices between $\mathrm{A}$ and $\mathrm{B}$ and between $\mathrm{C}$ and $\mathrm{D}$ :

$$
\begin{aligned}
& \mathrm{A}:(\$ 3,000, .90 ; \$ 0, .10) \text { vs. B: }(\$ 6,000, .45 ; \$ 0, .55) \text {; } \\
& \mathrm{C}:(\$ 3,000, .02 ; \$ 0, .98) \text { vs. D: }(\$ 6,000, .01 ; \$ 0, .99) \text {. }
\end{aligned}
$$

Choice $\mathrm{A}$ is interpreted as a $90 \%$ chance of winning 3,000 dollars and a $10 \%$ chance of winning nothing. By the independence axiom, people should either choose A and C or B and D. (For both choices, one alternative offers twice the amount of money as the other choice, but with only half the probability of winning the money.) In opposition to the independence axiom, the majority of people given these gambles choose $\mathrm{A}$ over $\mathrm{B}$, and $\mathrm{D}$ over C. Rubinstein's (1988) conjecture is that the difference between the two choice settings is that in C versus $D$, the probabilities are similar (.01 vs. .02), and that therefore more weight is given to amount (which favors D). Shafir, Osherson, and E. E. Smith (1993) have proposed a descriptive account of choice that weights both relative probabilities as well as absolute differences in probability, allowing the model to account for many violations of the independence axiom, including Rubinstein's results. Both ideas accomplish value-specific weighting.

Intransitivities in a set of choices provide another example of attribute weighting that depends on the set of compared entities. Tversky (1969) presented participants with a series of choices like the ones in Table 1, in which Choice A, for example, represents a 7/24 chance of winning $\$ 5$ and a $17 / 24$ chance of winning $\$ 0$. He observed the following intransitivities: People preferred $A$ to $\mathrm{B}, \mathrm{B}$ to $\mathrm{C}, \mathrm{C}$ to $\mathrm{D}$, and $\mathrm{D}$ to $\mathrm{E}$, but they preferred $\mathrm{E}$ to $A$. One interpretation of this result is that only differences along a dimension that exceed a certain criterion may be registered as important. Small differences along

Table 1

Choice Set Used by Trersky (1969)

\begin{tabular}{ll}
$\mathrm{A}$ & $(\$ 5.00,7 / 24 ; \$ 0,17 / 24)$ \\
$\mathrm{B}$ & $(\$ 4.75,8 / 24 ; \$ 0,16 / 24)$ \\
$\mathrm{C}$ & $(\$ 4.50,9 / 24 ; \$ 0,15 / 24)$ \\
$\mathrm{D}$ & $(\$ 4.25,10 / 24 ; \$ 0,14 / 24)$ \\
$\mathrm{E}$ & $(\$ 4.00,11 / 24 ; \$ 0,13 / 24)$ \\
\hline
\end{tabular}

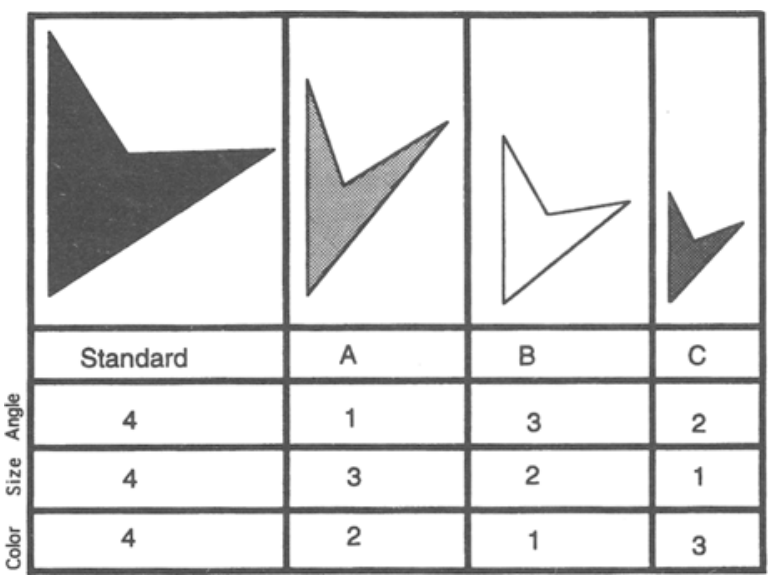

Figure 2. Stimuli used to examine intransitivities in similarity judgments. In successive forced-choice judgments between pairs of objects, there is a tendency for subjects to select $B$ over $A, C$ over $B$, and A over $C$ as more similar to the standard.

an important dimension are "edited out" or ignored. While probability information is ignored when adjacent options are compared, it is considered fully when Choices $\mathrm{A}$ and $\mathrm{E}$ are compared.

Two of the present authors (Goldstone \& Medin) have recently completed a similarity-judgment study modeled after an example from Arrow (1951) involving paradoxes associated with voting aggregation. In this more recent study, people are asked which of two alternatives is more similar to the standard. As illustrated in Figure 2, the standard is compared to Items A, B, and C. In general, when any two alternatives are presented, subjects can choose either the item that is closer to the standard on two out of three dimensions (a number-ofdimensions strategy) or the item that is much closer to the standard on the dimension with the largest difference (a largest-dimensional-difference strategy). For example, $B$ is much closer to the standard than is A on the dimension with the largest difference - that of angle - but $\mathrm{A}$ is somewhat closer than B on the other two dimensions. Consistent application of either of the above strategies would result in systematic intransitivities. Using largest dimensional difference as the criterion, $B$ should be chosen over A, C over B, and A over C. Using number of dimensions as the criterion, exactly the opposite pattern should be obtained. The particular dimension values were customized for each individual subject, so that angle, size, and color differences were approximately equally salient.

The results showed systematic intransitivities with both strategies, with more intransitivities in accordance with the largest-dimensional-difference strategy. The number of choices (out of a total of 144) consistent with a largest-dimensional-difference strategy was computed for each of the subjects. If subjects showed no susceptibility to intransitivities, the expected frequency of largestdimensional-difference responses would follow a binomial 
distribution with a mean of 72 . If there are no intransitivities in similarity, we would expect very few subjects (fewer than 1 out of the 58 tested subjects) to produce more than 90 or fewer than 54 largest-dimensionaldifference responses. In contrast to this prediction, quite a few subjects $(n=20)$ made more than 90 such responses, and some $(n=4)$ made fewer than 54 .

The prevalence of intransitive responses in similarity judgments parallels the intransitivity found in decision making. In both cases, a large difference between choices on a dimension is more influential than is expected by the additive effect of smaller differences on the same dimension. More generally, these results show statistically reliable intransitivities, consistent with value-specific dimension weighting in both similarity and choice contexts.

\section{Choice Similarity}

Tversky's pioneering studies of the dynamic character of similarity (Tversky, 1977; see also Tversky \& Gati, 1978 ) included the idea that categorization affects similarity. This idea, referred to as the diagnosticity hypothesis, is that features used as the basis for categorization acquire diagnostic value and increase the similarity of the objects that share them. This concept may be simply operationalized as follows: In one condition, participants are asked to sort stimuli into groups of equal size, and in another, participants are asked to make similarity judgments. For example, given the set consisting of Israel, Syria, Iran, and England, $72 \%$ of the participants put Israel and England into the same category, but given the set consisting of Israel, France, Iran, and England, only $16 \%$ put England and Israel together. In the similarity-judgment condition, subjects decided which of the three countries was most similar to a standard (Israel). The percentage of times each country was selected as most similar to Israel is shown in the top sets in Table 2. The relative choices of England versus Iran shifted as a function of the comparison context. One measure of diagnosticity consists of the percentage of choices of the diagnostic alternative (as defined by the sorting task [i.e., England in Set 1 and Iran in Set 2] as being most similar to the standard) minus the percentage of choices of the nondiagnostic alternative; that is, $(38 \%-38 \%)+$ $(46 \%-24 \%)=22 \%$. The middle sets of Table 2 show results from another pair of contexts which yielded an even larger diagnosticity effect $(59 \%)$. Overall, Tversky and Gati (1978) found a reliable diagnosticity effect (using this measure) across 20 sets of countries. Glucksberg and Keysar (1990) also reported reliable diagnosticity effects with literal and metaphorical contexts (see the bottom sets in Table 2, which show a 34\% diagnosticity effect).

Tversky's (1977) interpretation of these effects is that changes in feature salience modify the importance of particular matching and mismatching features. In Glucksberg and Keysar's (1990) study, for example, in the context including pimples, the feature corresponding to "artifact versus natural" would be salient, whereas in the context including statues, the feature corresponding to "attractiveness versus ugliness" would be salient.

Suppose, however, that we view these context effects from the perspective of decision making. Consider the idea that the middle context item is an alternative that competes with the other items to be selected. That is, one could think of the diagnosticity contexts as a way of examining similarity effects in choice (as in studies aimed at demonstrating violations of Luce's [1959] constantratio rule [Tversky, 1972]). In this case, the middle item should take more choices from the alternative that is similar to it than from the alternative that is dissimilar to it. In the domain of decision making, this pattern of data is referred to as a substitution effect. For example, one could view the results shown in the last sets in Table 2 as indicating that pimples take choices that would have gone to warts and that statues takes choices that would have gone to paintings. This prediction is made by Tversky's elimination-by-aspects (Tversky, 1972) and preferencetree (Tversky \& Sattath, 1979) models. In both models, each choice is represented as an ensemble of aspects, and at each stage in the decision, one eliminates all of the choices that do not have a selected aspect. Pimples takes more choices from warts than from paintings because pimples and warts would both be candidates if the ugly feature were selected as the basis of choice, but if the ar-

Table 2

Examples of Diagnosticity Sets Taken from Tversky and Gati (1978), Tversky (1977), and Glucksberg and Keysar (1990)

\begin{tabular}{|c|c|c|c|c|c|}
\hline \multicolumn{3}{|c|}{ Set 1} & \multicolumn{3}{|c|}{ Set 2} \\
\hline Standard & Stimulus & Judged Most Similar* & Standard & Stimulus & Judged Most Similar \\
\hline 1. Israel & $\begin{array}{l}\text { England } \\
\text { Syria } \\
\text { Iran }\end{array}$ & $\begin{array}{l}38 \\
24 \\
38\end{array}$ & Israel & $\begin{array}{l}\text { England } \\
\text { France } \\
\text { Iran }\end{array}$ & $\begin{array}{l}24 \\
30 \\
46\end{array}$ \\
\hline 2. Austria & $\begin{array}{l}\text { Sweden } \\
\text { Poland } \\
\text { Hungary }\end{array}$ & $\begin{array}{l}49 \\
15 \\
36\end{array}$ & Austria & $\begin{array}{l}\text { Sweden } \\
\text { Norway } \\
\text { Hungary }\end{array}$ & $\begin{array}{l}14 \\
26 \\
60\end{array}$ \\
\hline 3. Billboards & $\begin{array}{l}\text { Paintings } \\
\text { Pimples } \\
\text { Warts }\end{array}$ & $\begin{array}{l}58 \\
11 \\
31\end{array}$ & Billboards & $\begin{array}{l}\text { Paintings } \\
\text { Statues } \\
\text { Warts }\end{array}$ & $\begin{array}{l}33 \\
27 \\
40\end{array}$ \\
\hline
\end{tabular}

*Percentage of participants who judged the stimulus to be most similar to the standard for that set. 
tifact feature were selected, paintings would have no remaining competitor.

How can one determine whether there are diagnosticity effects over and above the substitution effects predicted by these models? A conservative criterion is that the choices of the diagnostic alternative in the two contexts must sum to greater than $100 \%$. For instance, in the billboards example, if the sole function of pimples were to take choices from warts, the absolute number of choices of paintings should not be enhanced and the same should hold for choices of warts in Set 2. Using the $100 \%$ criterion would rule out any contribution of substitution effects, but would likely underestimate diagnosticity effects. Unambiguous evidence for enhancement is found in the sets of countries in the middle groups of Table 2, in which Poland and Hungary together account for $51 \%$ of the choices in Set 1, while Hungary alone accounts for $60 \%$ of the choices in Set 2 . In this case, the increase in choice of Hungary when it is the diagnostic alternative cannot be explained in terms of lack of competition from Poland because that factor could only account for up to $51 \%$ of the choices. Overall, the diagnostic alternative is selected for a total of $109 \%(49 \%+60 \%)$. Note, however, that the corresponding sums in the top and bottom sets in Table 2 are $84 \%$ and $98 \%$, respectively - both less than the $100 \%$ criterion. Since Tversky and Gati (1978) reported only the diagnosticity scores for the other 18 country comparisons, it is not possible to determine whether there is a diagnosticity effect that cannot be attributed to substitution.

Recently, Medin and Kroll (1994) examined diagnosticity effects using geometric forms having as stimuli varying degrees of attributional and relational similarity. For example, in Figure 3, Set 1, A shares the relation "same shading," and C the relation "above," with the standard. The third choice, B, varies across sets such that $C$ should be the diagnostic alternative in Set 1 and A the diagnostic alternative in Set 2. Participants were asked to rank order the similarity of the alternatives with respect to the standard. Overall, the diagnostic alternative was ranked above the nondiagnostic alternative $55 \%$ of the time, a reliable effect. The relative ranking measure eliminates the context (B) item from consideration, and therefore the diagnosticity effect is not attributable to substitution. In short, it appears that there are diagnosticity effects that cannot be explained in terms of substitution; however, as we shall shortly see, there may be other interpretations of diagnosticity.

\section{Attraction, Compromise, Diagnosticity, and "Reasons"}

Attraction. A paradoxical finding has recently been uncovered in the decision-making literature. Specifically, adding an alternative similar to one item from the original choice set may actually boost choices of that original-choice item (Huber, Payne, \& Puto, 1982; Huber \& Puto, 1983; Simonson \& Tversky, 1992). This phenomenon (the attraction effect) violates the assumption of regularity (i.e., that adding a new alternative cannot increase the probability of choosing a member of the original set), which is crucial for the validity of most probabilistic-choice models. Figure 4 (for the moment ignoring Item $T$ ) illustrates the conditions under which attraction effects are reliably obtained. The key feature is that the added alternative (C or D) is asymmetrically dominated by one of the original choice options (namely, the most similar one). Adding $C$ increases the number of times $A$ is chosen, and adding $D$ increases the number of times $B$ is chosen, relative to original $(A, B)$ choice context. Huber and Puto (1983) found that an added alternative could produce attraction effects when it was simply relatively inferior and technically not asymmetrically dominated.

What is responsible for attraction effects? Several decision researchers have advanced the idea that when preference is uncertain (i.e., no dominating alternative is present), choices may be determined not by direct preferences but rather by the justifications or reasons for choosing or avoiding alternatives (Montgomery, 1983;

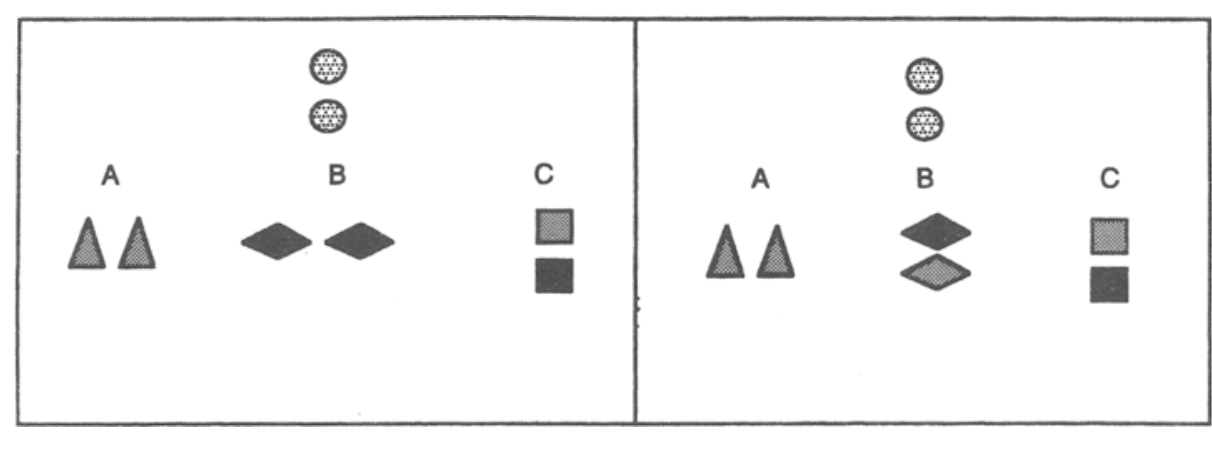

Set 1

Set 2

Figure 3. Sample stimuli from the study of diagnosticity effects using relational properties. In Set 1, Choice C is the only alternative that shares an above relation with the standard. In Set 2, Choice $A$ is the only alternative that shares a same-shading relation with the standard. 


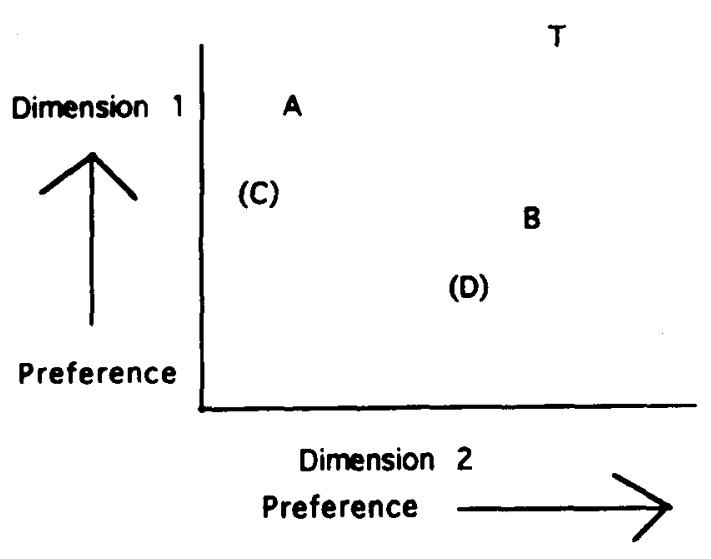

Figure 4. Paradigm for attraction effects.

Shafir \& Tversky, 1992; Slovic, 1975; Slovic, Fischhoff, \& Lichtenstein, 1982). Simonson (1989) suggested that attraction effects may be mediated by the fact that the decision maker notes that one choice clearly dominates at least one of the alternatives, providing a simple reason for selecting the dominating alternative. In support of that hypothesis, Simonson found that attraction effects were reliably larger when people knew they would have to justify their choices than when they knew they would not have to justify their choices.

Aakers (1991) also found an attraction effect under high-justification conditions (see also Heath \& Chatterjee, 1991; Ratneshwar, Shocker, \& Stewart, 1987, for other relevant observations concerning attraction effects). Interestingly, however, Aakers observed negative attraction under conditions of low justification. Although there are numerous differences between Simonson's (1989) and Aakers' (1991) studies that may account for the differing results under low justification, we wish to call attention to the fact that negative attraction in choice corresponds to true diagnosticity effects in similarity judgments (Aakers ruled out substitution effects by using a rating measure). That is, if we make a correspondence between similarity and preferability, a negative attraction effect would be analogous to Tversky's (1977) observed diagnosticity effect.

These parallels lead to the speculation that attraction effects could be obtained in similarity judgments. Figure 4 shows a straightforward way to map the preference task onto similarity judgments. The task is to indicate which alternative (A or B) is most similar to the standard $(\mathrm{T})$, where the choice context includes either $\mathrm{C}$ or $\mathrm{D}$. Interestingly, attraction effects in similarity judgments would likely correspond to negative diagnosticity effects, because $B$ and D would be likely to be sorted together in the set consisting of $\mathrm{A}, \mathrm{B}, \mathrm{D}$, and $\mathrm{T}$, while $\mathrm{A}$ and $C$ would likely be put in the same category for the set A, B, C, and T. Using essentially this design, Medin, Pineda, and Markman (1994) have obtained very strong attraction effects in similarity judgments.
Compromise. Simonson (1989) provided further evidence for the importance of justification in judgments by demonstrating another interaction between the items in a choice set. Consider a situation with nondominated alternatives, $\mathrm{A}$ and $\mathrm{B}$, in which a third option, $\mathrm{C}$, is added that is least favorable on one dimension and most favorable on the other dimension (see Figure 5). Simonson reasoned that in this context, the alternative most similar to the new choice (in this case, B) might be selected with the justification that it now represents a compromise between alternatives that are high on one dimension and low on the other. He observed reliable compromise effects that increased when people knew that they would have to justify their choices.

As in the case of attraction effects, one can test for compromise effects in similarity judgments by creating a standard and a set of alternatives. For example, if some standard high on both dimensions were added to Figure 5 , one might anticipate that the probability of choosing $\mathrm{B}$ as most similar to $\mathrm{T}$ in the choice set consisting of $\mathrm{A}, \mathrm{B}$, and $\mathrm{C}$ might be greater than when the choice set is restricted to just A and B. Again, Medin et al. (1994) have recently observed reliable compromise effects in similarity judgments.

Diagnosticity revisited. Consider Figure 3 again and imagine that participants are asked to select the alternative that is least similar to the standard. According to the diagnosticity hypothesis, an alternative should be less likely to be selected as least similar when it shares diagnostic features with the target. A contrasting prediction can be derived from the idea that people want a reason to justify their judgments (Simonson, 1989). For instance, given Set 1 from Figure 3, a reason to pick $C$ as most different is that it is the only alternative not having the relation "same shading." In Set 2, A is the only choice not having the relation "above." In short, the "wanting a reason" view leads to the prediction that diagnostic alternatives may be picked both as most similar to and as most different from a standard. In preliminary observations, Medin and Kroll (1994) have found that the diagnostic alternative is selected as most differ-

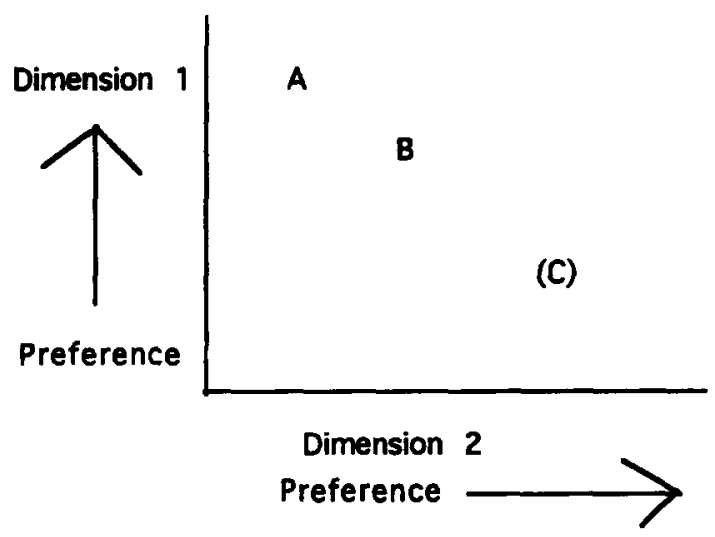

Figure 5. Paradigm for compromise effects. 
ent for a mean total of $104 \%$, consistent with the idea that reasons are guiding judgments. (This figure is not reliably above $100 \%$, so these data can only be taken as suggestive.)

In choice contexts in which substitution effects are found, one wonders what might happen if participants were asked which alternative they least preferred. If people are looking for justifications for their judgments, adding an alternative $\mathrm{Z}$ similar to $\mathrm{X}$ might lead to more choices of $Y$ as least preferred, compared with the number of times $Y$ is chosen in the two-alternatives ( $\mathrm{X}$ vs. $\mathrm{Y}$ ) choice context.

\section{Summary of Weighting Effects}

So far, our review has suggested that the weighting of dimensions is dynamic and context dependent for both similarity and choice. Furthermore, the processing principles underlying weighting appear to be comparable at a more specific level of detail (e.g., compatibility, reasons). We turn now to questions of comparability or alignability of choices, a process which has often been taken for granted in both domains. As we shall see, current work reveals the dynamic character and importance of comparison processes.

\section{Alignment and Comparison}

\section{Common Currency}

Early work in both similarity judgments and decision making made an assumption of "common currency," according to which all factors can be framed in comparable units. For decision making, the units are "utilities," and it was assumed that all costs and benefits could be translated into utilities. In similarity judgments, the common metric was either distance (for multidimensional scaling) or featural overlap (for feature-based models). One problem with this view is that not all comparisons are equally easy to make; comparisons that involve substantially different properties are difficult. It is easier, for example; to compare the merits of Mendelssohn and Schumann than to compare the merits of Schumann and the Beatles. It may be possible to convert both Schumann and the Beatles into generic utilities, but this process seems to require more work than comparing items that have similar aspects. This example provides an initial indication that decision making may not proceed by automatically converting alternatives into a generic metric.

Framing effects also suggest that choices are not converted into a generic metric. When bidding for the opportunity to play a gamble, the potential gain from the gamble is emphasized; when choosing between gambles, the probability of winning is emphasized. If alternatives were automatically converted into utilities, information about how the utility was achieved (e.g., high probability vs. high potential gain) would be discarded. Context and framing effects eliminate the possibility of creating simple translations between aspects. For example, a statement that applies in the bidding scenario, such as "increasing the probability of winning by $5 \%$ is equal to a $\$ 10$ increase in payoff," will not apply in the choice situation.

Likewise, in similarity judgments, the prospects for a single currency are not encouraging. As William James $(1892 / 1989)$ pointed out, the moon is like a ball (because both are round), and the moon is like a lamp (because both are bright), but a lamp and a ball are not at all similar. Tversky and Gati (1982) presented a number of similar examples as demonstrations of violations of the metric axioms underlying mental-distance models of similarity. Fillenbaum and Rapoport (1974) asked a linguist for similarity ratings between verbs. From these data, they argued that the linguist had many similarity criteria, and that the criteria used for a given judgment depended on the particular items being compared. For example, acquit was judged to be similar to clear because both are synonyms; acquit was judged to be similar to convict because both are alternatives from the same class; and apologize was judged to be similar to forgive because one has the other as its goal. Likewise, different methods for obtaining comparison data reveal different values. For example, shared features are more important for similarity ratings, while unique features are more important for dissimilarity ratings (e.g., Gati \& Tversky, 1982). Thus, we cannot construct a generic translation such as "two shared features are as influential as three distinctive features."

A generalization of many of the results from the literature on similarity judgments and on decision making is that comparisons tend to be made at the most concrete level possible (e.g., Payne \& Bettman, 1992). Abstract values can be assigned to dimension values, but this takes effort and may not be intuitive. If possible, items are compared on the basis of specific features, such as "A has more years teaching experience than B." Only when required by lack of agreement on particular dimensions do comparisons involve abstract assessments of the overall value of items.

\section{Structural Alignment, Similarity Judgments, and Decision Making}

It seems fairly uncontroversial that when one assesses a bet, one compares probabilities with probabilities and amounts with amounts, and that when one judges forms varying in color and shape, one compares colors with colors and forms with forms. Recent studies of similarity have led to the outlines of a process model for comparison (Gentner \& Markman, in press; Goldstone, 1994b; Goldstone \& Medin, 1994a, 1994b; Markman \& Gentner, 1993a; Medin, Goldstone, \& Gentner, 1993). According to this view, similarity comparisons involve a process of structural alignment akin to the one proposed to mediate analogical reasoning (Gentner, 1983, 1989). Briefly, this view assumes that objects (or choices) are represented by hierarchical relational structures that explicitly encode relations between dimensions as well as connections between dimensions and their values. 
The output of the comparison process consists of a set of commonalities as well as two kinds of differencesalignable differences and nonalignable differences (Markman \& Gentner, 1993a). Alignable differences are related to the commonalities of a pair; that is, two choices having different values along a common dimension (e.g., different prizes in two lotteries) would constitute an alignable difference. In contrast, nonalignable differences are unrelated to the commonalities of a pair; that is, one choice having a value along a unique dimension would constitute a nonalignable difference.

Structural alignment has two key aspects that are important for this discussion. First, it predicts that cognitive processes should treat alignable and nonalignable differences in different ways; and second, it suggests that similarity (patterns of matching and mismatching attributes and relations) and alignment interact dynamically. These predictions have been tested directly in the similarity literature, and we will first present a discussion of some of this research. Following that, we will present some phenomena in decision making that we think are compatible with this view of comparison.

Alignment in similarity. Much evidence suggests that the structural-alignment process entails global constraint satisfaction rather than local matching (e.g., Falkenhainer, Forbus, \& Gentner, 1989; Medin et al., 1993). For example, Markman and Gentner (1993b) asked people to point to the feature in one scene that "went best" with a specified feature in a second scene. People tended to select the most similar object from the other scene. However, if people first made similarity judgments before being asked to point to correspondences, their choices were based on the object in the second scene that played the same role as the object in the first scene. In other work, Goldstone and Medin (1994a, 1994b) required participants to make similarity or sameness-difference judgments under different deadlines. For short deadlines, performance was a function of the total number of matches between the stimuli being compared. At longer deadlines, performance was increasingly likely to be a function of matches in corresponding roles and relations rather than of just the sheer number of matches.

Although there is a sense in which feature-matching models like Tversky's (1977) contrast model perform alignments between features, current evidence points to the need for detailing and examining the implications of the alignment processes. While the contrast model might be said to align common features, evidence suggests that the extent to which two common features are placed in alignment depends on whether they are consistent with (and connected to) other alignments that are simultaneously being created (Clement \& Gentner, 1991; Goldstone, 1994b; Markman \& Gentner, 1993a). In order to know how important a particular shared feature is for increasing similarity, one must know how similar the parts are that possess the shared features, how similar other pairs of parts are, and which part-to-part alignments are (in)consistent with other part-to-part alignments. That is, alignment is based on global constraint satisfaction rather than on the best local matches.

Markman and Gentner (1993b) provided specific evidence for the distinction between alignable and nonalignable differences in comparisons. Participants were asked either to list commonalities and differences of word pairs or to rate their similarity. The pairs were selected so as to differ widely in their similarity. The two findings of particular interest are that, as indicated by regression analyses, alignable differences and nonalignable differences were given different weight in reducing similarity, and that the kinds of differences listed for a pair depended on the similarity of the words in the pair. Similar pairs had more listed alignable differences than did dissimilar pairs, but they also had fewer listed nonalignable differences than did dissimilar pairs. These observations both reinforce the role of alignment in comparisons and indicate the need to distinguish between alignable and nonalignable differences. Finally, these results suggest that the ease of comparison affects the availability of alignable differences, which in turn affects similarity or other processes (such as choice) that involve comparisons.

Alignment in choice. Although structural alignment has not been tested explicitly in a decision-making context, there is some evidence that alignment affects choice behavior. For example, Table 3 shows a pair of complex options studied by Tversky and Kahneman (1986). Participants were told that each option corresponded to a separate box of marbles with the proportion of different colors and associated outcomes as shown in the table. Separate groups were shown either A and B or $\mathrm{C}$ and $\mathrm{D}$. If corresponding colors are aligned, it is easy to see that Option A dominates Option B, the only differences being the outcomes associated with a green or blue marble. Option $\mathrm{C}$ in the second gamble can be created by painting the green marble red and the blue marble green, while leaving the payoffs attached to each marble unchanged. Similarly, Option D can be created from $B$ by painting the blue marble yellow and leaving the payoffs intact. In short, the overall probabilities and payoffs are identical for $\mathrm{A}$ and $\mathrm{C}$ and for $\mathrm{B}$ and $\mathrm{D}$, and, therefore, Option $\mathrm{C}$ dominates Option D just as Option $\mathrm{A}$

Table 3

Choice Options Used by Tversky and Kahneman (1986)

\begin{tabular}{cccccc}
\hline & \multicolumn{5}{c}{ Marbles (\%) } \\
\cline { 2 - 6 } Option & White & Red & Green & Blue & Yellow \\
\hline A & 90 & 6 & 1 & 1 & 2 \\
Outcome & $\$ 0$ & Win $\$ 45$ & Win $\$ 45$ & Lose $\$ 10$ & Lose $\$ 15$ \\
B & 90 & 6 & 1 & 1 & 2 \\
Outcome & $\$ 0$ & Win $\$ 45$ & Win $\$ 30$ & Lose $\$ 15$ & Lose $\$ 15$ \\
C & 90 & 7 & 1 & & 2 \\
Outcome & $\$ 0$ & Win $\$ 45$ & Lose $\$ 10$ & & Lose $\$ 15$ \\
D & 90 & 6 & 1 & & 3 \\
Outcome & $\$ 0$ & Win $\$ 45$ & Win $\$ 30$ & & Lose $\$ 15$ \\
\hline
\end{tabular}


dominates Option B. Note, however, that if matching colors are aligned, the biggest difference in the values of corresponding dimensions is now associated with the green marble, for which Option D has a much more favorable outcome. The participants in the group presented with the first gamble all chose A over B, but a majority $(58 \%)$ of the participants presented with the second gamble chose D over C. In this case, the most natural form of alignment has a striking effect on choices.

Johnson (1989) presented evidence that subjects' decisions are more likely to involve attributes of the objects when the items are easily alignable. Thus, when choosing between two toasters, the subject may explicitly consider the number of slots that each one has. In contrast, when selecting between a toaster and an iron, the number of slots in the toaster is no longer important; rather, subjects may focus on other issues, such as how much they need a toaster versus how much they need an iron. The importance of a feature in making a decision depends on whether the choices can be compared on the feature (see also Johnson, 1984, 1986). Russo and Dosher (1983) presented a similar argument to suggest that dimensional processing of alternatives will be preferred to holistic processing when the dimensions are easily compared, because dimensional processing often requires less effort.

Payne (1982, Payne \& Bettman, 1992) has suggested that the differing results from choice and judgment paradigms can be understood within the framework of similarity models. His idea is that in judgment contexts, people consider both common and distinctive features, while in choice contexts, they focus on distinctive features. People can make decisions either by comparing whole items to each other (holistic processing) or by comparing items feature by feature (attribute-based processing). Expected-utility theory assumes holistic processing; for example, if a person is deciding between a vacation in Africa and a vacation in Europe, in accordance with this theory, the expected utility of each vacation would be determined separately, with all of its attributes and their importance being taken into account. However, researchers have observed that people often use attribute-based processing (Hogarth, 1980; Payne, 1976; Russo \& Dosher, 1983). According to what Hogarth calls the additive-difference model, people make choices by comparing items on selected attributes; using this technique, a person might reason, "Africa would be more of an adventure and would be a more memorable experience; Europe would be culturally more interesting." This technique involves aligning the choices on dimensions. Payne found that this alignment strategy is particularly prevalent when people have many alternatives to examine and each alternative has many features. Hogarth observed that the additive-difference technique "can considerably ease information-processing demands since it involves comparing information that is commensurable" (p. 75).

Decision-making work in the area of "mental accounting" also supports an alignment process. The basic notion of mental accounting is that people establish separate "budget" entries for different types of costs, and that they prefer to compare items within these types (Thaler, 1985). Even when all entries involve the same type of cost (e.g., money), there is a tendency to compare equivalent entries. For example, Kahneman and Tversky $(1984$, p. 347) gave subjects the following scenario: "Imagine that you are about to purchase a jacket for $\$ 125$ and a calculator for $\$ 15$. The calculator salesman informs you that the calculator you wish to buy is on sale for $\$ 10$ at the other branch of the store, located 20 minutes drive away. Would you make a trip to the other store?" Subjects are more willing to make the trip in this scenario than in a scenario where the calculator is $\$ 125$ ( $\$ 120$ on sale) and the jacket is $\$ 15$. According to subjective-utility theory, these decisions should be equivalent, both trading off $\$ 5$ saved on a purchase total of $\$ 140$ for a 20 -minute trip. Instead of tabulating total cost, people seem to align comparable items and compare their prices. When calculators are aligned with calculators (and jackets with jackets), the difference between $\$ 10$ and $\$ 15$ seems more impressive than the difference between $\$ 120$ and $\$ 125$.

Even within a pair of choices, the relative attention given to comparable and noncomparable dimensions may be important. For example, Slovic and MacPhillamy (1974) asked participants to rate students who had scores on one common dimension (e.g., English skills) and one unique dimension (e.g., achievement need for one student and quantitative skills for the other). When a dimension was common, it received much more weight than it did when it was unique. Cautioning participants not to increase the weight of the common dimension did not reduce the effect.

Alignment of choices may also underlie a well-known violation of expected-utility theory's substitutability assumption. According to substitutability, if Options A and $B$ are equally preferred, and Options $A$ and $C$ are equally preferred, Options B and $C$ should be equally preferred. However, one can imagine a situation where a trip to Rome (Option A) and a trip to Paris (Option B) are equally attractive. Furthermore, if these trips are equally preferred, it is reasonable to think that the choice between a trip to Paris plus one dollar (Option C) and a trip to Rome is just as difficult to make. One would expect the addition of one dollar to be almost completely insignificant for the decision. However, given a choice between a trip to Paris and a trip to Paris plus one dollar, the latter alternative strongly dominates. This result is predicted from an alignment perspective. The choice between Paris and Paris $+\$ 1$ involves items that are easily placed in alignment. When the two "Paris" aspects are aligned, the remaining $\$ 1$ of Option $C$ is salient. Greater sensitivity for detecting utility differences in choices is predicted if the choices can be aligned.

The idea that people align and compare specific features is, of course, the basis for the effects of choice similarity described earlier in this paper. In Tversky and Sattath's (1979) preference-tree model (a specialization of 
T'versky's (1972) elimination-by-aspects model), aspects are assumed to be hierarchically organized. For example, in deciding which famous person they would like to talk to, people may first choose politicians over movie stars and then consider particular individuals. Thus, a natural consequence of a hierarchical decision procedure is that alternatives that are easily alignable will be compared. It may be difficult for a person to choose between meeting Mahatma Gandhi and Charlie Chaplin because of their many differences; the person may complain that they are being asked to "compare apples and oranges." Choosing between Gandhi and Winston Churchill is more reasonable because the men can be compared on comparable aspects such as vision, political acumen, and integrity. By eliminating entire branches of a decision tree at each processing stage, it is guaranteed that the final choice will be between similar items. Johnson (1989) found evidence for this style of processing in a consumer-choice situation. Subjects who were given a heterogeneous choice set (e.g., two different toasters and two different smoke alarms) initially used holistic processing and abstract attributes to select one of the homogeneous subgroups. Then, faced with a decision between more similar products, subjects switched to attribute-based processing to choose one product. Of course, a hierarchical system adds a layer of complexity to the alignment-and-comparison process. In similarity judgments, things are at least as complex.

Taken together, the evidence presented in this section suggests that it is plausible to consider the comparisons involved in similarity judgments and decision making as alignments of representational structure. In the next section, we consider some further implications of this view.

\section{Summary of Alignment and Comparison}

Once again, there are suggestive correspondences between similarity judgments and decision making. These parallels are very strong for value-specific feature weighting and compatibility effects. Furthermore, there are numerous potential parallels that remain to be explored, especially in the case of differential weighting of identity on a dimension.

\section{Comparison Asymmetries}

\section{Reference Points and Asymmetries}

Asymmetries in judgment may arise from comparison order. Houston, Sherman, and Baker (1989) had subjects choose which of two objects (persons, vacations, automobiles, etc.) they preferred. Houston et al. observed that the object that was presented second was particularly salient. When objects shared good features and had unique bad features, there was a tendency to select the first object, presumably because the distinctive bad features of the second object were salient. When objects shared bad features and had unique good features, there was a tendency to select the second object. Houston et al. argue that the second object acts as a reference point for the comparison, and so aspects that are not part of the second object's representation are often ignored.

Interestingly, there is some evidence that this asymmetry interacts with the comparability or alignability of the alternatives. Sanbonmatsu, Kardes, and Gibson (1991) performed the same task as Houston et al. (1989), but varied whether the nonshared feature came from the same dimension or from different dimensions. The asymmetry in choice was found when nonshared features came from different dimensions, but not when they came from the same dimension. That is, the asymmetry appeared to be driven by nonalignable differences.

Asymmetries associated with alignable differences may be obtained when there are natural reference points. For example, the number 996 is judged to be more similar to the number 1,000 than 1,000 is to 996 (Rosch, 1975). By the same token, the framing of decisions may suggest different reference points and give rise to asymmetries. For example, Loewenstein (1988) found that people expected a far higher compensation to delay receiving a purchased good than they were willing to pay to have the delivery of a purchased good speeded up (see Payne \& Bettman, 1992, for further examples).

\section{Asymmetries in Similarity}

Similarity comparisons may also exhibit asymmetries. For example, people rate the similarity of the United States to Mexico to be less than the similarity of Mexico to the United States (Tversky, 1977; Tversky \& Gati, 1978). In general, Tversky found that a less prominent object is judged to be more similar to (and less different from) a prominent one than a prominent object is to a less prominent one. Markus and Kitayama (1991) also report asymmetries in the social domain that are sensitive to reference points. They argue that Western cultures focus on the self, whereas Eastern cultures make others more salient. They report a study by Kitayama, Markus, Tummala, Kurokawa, and Kato (1990) in which students from Eastern and Western cultures judged the similarity of the self to others and of others to the self. Western students rated the similarity of self to others to be substantially less than the similarity of others to self. Eastern students showed the opposite asymmetry.

Asymmetries may be produced in part by a differential weighting of the distinctive features of the referent relative to the distinctive features of the alternative. Recently, however, Medin et al. (1993) have shown that even the matching of common features accessed in a comparison may depend on the direction of the comparison. Specifically, in comparing $\mathrm{A}$ to $\mathrm{B}$, the common features that participants list tend to be more closely associated with the base (B) term than with the target (A) term. For example, "found on farms" is a feature common to cows and dogs, but it is judged to be more closely associated with the former; consequently, subjects are more likely to list this feature as a shared property when asked to compare dogs with cows than when asked to compare cows with dogs. Therefore, asymme- 
tries may potentially arise from both common and distinctive features.

\section{The Endowment Effect}

One of the most robust findings in decision-making research is that people prefer what they have (i.e., the status quo) to alternatives. For example, Knetsch and Sinden (1984) gave experimental participants either $\$ 2$ or a lottery ticket and some time later gave them a chance to trade the $\$ 2$ for a lottery ticket or the lottery ticket for $\$ 2$. Very few participants chose to switch.

Another example comes from a series of experiments by Kahneman, Knetsch, and Thaler (1990). In one experiment, college students were assigned to one of three conditions. Those in the "seller" condition were given a coffee mug and then asked if they would be willing to sell it at each of a series of prices ranging from 25 cents to $\$ 9.25$. The second group, the "buyers," were asked whether they would be willing to buy the mug at the same set of prices. The third group, "choosers," were not given a mug but were asked, for each of the alternatives, to choose whether they preferred the mug or the amount of money. Interestingly, the sellers and the choosers were in the same situation, in that they were choosing between receiving (or keeping) the mug or the money. The median prices required for choosing the money, however, were substantially higher for the sellers $(\$ 7.12)$ than for the choosers $(\$ 3.12$; the median for the buyers was \$2.87). Again, this observation suggests that owners are reluctant to part with what they have.

The cause of these instant-endowment effects is not immediately evident. Some researchers (e.g., Kahneman et al., 1990; Tversky \& Kahneman, 1991) have suggested that the key factor is loss aversion-that is, that the disadvantages of a change loom larger than its advantages. The current situation acts as a reference point against which alternatives are evaluated. In other cases, there may be hidden costs to changing the status quo (e.g., changing jobs not only alters one's work environment, but also requires finding a new route to commute and learning new office procedures).

Do endowment effects and asymmetries of similarity comparison represent the same sort of phenomenon? The answer is far from clear. The Kahneman et al. (1990) interpretation in terms of loss aversion is consistent with the idea that greater weight is given to the positive qualities of endowed entities. Imagine a situation in which the endowed entity and the alternative had distinctive negative features. If the focus were on the distinctive features of the referent, one might imagine that a negative item would seem quite unpleasant, and that subjects might therefore be eager to be rid of it. We know of no clear evidence on this hypothesis (but see Beike \& Sherman, 1993, for some initial observations).

\section{Constructive Processes}

\section{The Creation of New Aspects}

So far, we have discussed constructive processes in terms of feature weighting. Although theories in deci- sion making and similarity judgments have progressed significantly from their early incarnations, there now exists a substantial body of literature, including the work cited earlier, that gives grounds for revising our current theories in these areas. Interestingly, the prescribed revisions are quite similar for the two domains.

There is also evidence in favor of the more radical hypothesis that aspects are created, not just weighted differently, during judgments. Medin et al. (1993) asked subjects to list similarities and differences between pairs of objects such as those shown in Figure 6. For some comparisons, one of the items had an ambiguous interpretation. The ambiguous item was given mutually inconsistent feature interpretations depending on the item with which it was paired. In Figure 6a, the top item tended to be interpreted as possessing three prongs when it was compared with the left object that clearly possessed three prongs, and was interpreted as possessing four prongs when compared with the four-pronged object on the right. It seems that the representation of the top item depends on its partner in comparison. ${ }^{1}$ The ambiguous item's interpretation becomes assimilated to the unambiguous item's interpretation.

The assimilation of ambiguous items to unambiguous items is found in decision-making paradigms as well. Herr, Sherman, and Fazio (1983) primed subjects with animals of different levels of ferocity, and later asked them to rate the ferocity of either ambiguous animals (e.g., a fictional animal such as a "lemphor") or unambiguous (real) animals. When moderate levels of ferocity were primed, ambiguous items were assimilated to the prime, while unambiguous animals were contrasted away from the prime. Thus, a "lemphor" was judged to
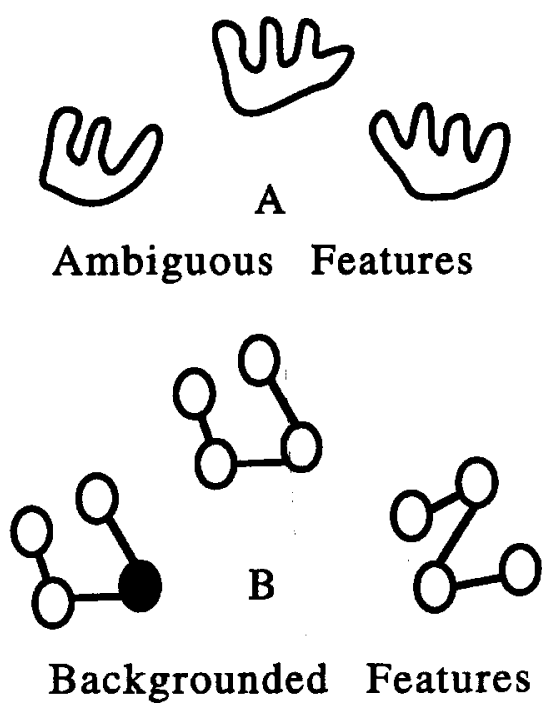

Figure 6. Figure 6a shows sets of stimuli in which the features that the unambiguous stimulus "has" depend on what it is compared with. Figure $6 \mathrm{~b}$ gives examples of stimuli in which common features appear to be presupposed or backgrounded; for example, few participants mention that the top and right-hand figures have all white circles. 
be more ferocious if preceded by several ferocious animals than if preceded by tamer animals. As with the similarity experiment, subjects' interpretations of ambiguous items are modified to be more similar to items in the same context.

Other experiments suggest that people spontaneously fill in missing information about an item, thus allowing all of the items that are presented to be compared on the same attributes (Levin, Johnson, \& Faraone, 1984; Yamagishi \& Hill, 1981). Levin et al. found that people often fill in missing information by assigning a constant context-independent value, but they also found evidence that subjects occasionally use interdimensional relations to fill in attribute values (e.g., subjects assume that a sample of beef is of low quality because it is inexpensive).

\section{Foreground and Background}

People create new stimulus aspects not only to increase the similarity of ambiguous items to comparison items, but also to apprehend differences between unambiguous comparisons. Medin et al. (1993) showed that some properties are not considered unless there is variation in the property. An example of such a "backgrounded" property is shown in Figure 6B. When subjects were asked to list the differences between the top object and the left object in this figure, the modal response included a statement such as "one has all white circles and the other has a black circle." However, the property of having all white circles was seldom listed as a similarity between the top and the right objects. Thus, if the task of listing similarities and differences between objects is assumed to provide an approximate measure of subjects' actively represented properties, properties seem to be created when they are brought to the subjects' attention by introducing variations in them.

If some stimulus aspects are not actively represented until variation on the aspect is observed, it should be possible to obtain violations of the monotonicity assumption. The assumption of monotonicity incorporated in both multidimensional-scaling and featural approaches to similarity states that increasing the number of shared features between two objects (or decreasing the number of distinctive features) should never decrease their similarity. Violations of this intuitive assumption should arise if different comparisons cause different properties to be generated. An abstract design for obtaining violations of monotonicity is shown in Figure 7A. The stimuli A, B, and $\mathrm{C}$ are described by their values on two dimensions. $B$ and $C$ are far removed from $\mathrm{A}$ on Dimension X, while on Dimension Y, A and B have the same value and $C$ has a slightly greater value. Figure 7B (in which Dimension $\mathrm{X}$ is arrow orientation and Dimension $\mathrm{Y}$ is angle of arrowhead) shows an instantiation of this design.

According to the assumption of monotonicity, the similarity of $\mathrm{A}$ and $\mathrm{C}$ should never be greater than the similarity of A and B. However, recently, Goldstone, Halberstadt, and Medin (1994) were able to find this pattern of results. When Dimension $\mathrm{Y}$ was a dimension that was likely to be backgrounded, subjects who rated the similarity of $\mathrm{A}$ to $\mathrm{C}$ gave higher ratings than subjects who rated the similarity of $\mathrm{A}$ to $\mathrm{B}$.

The observed nonmonotonicity can be partially explained in terms of subjects adopting a process whereby differences across dimensions are integrated to form a judgment; that is, subjects could reason, "A and C are far apart as far as the direction in which they are pointing is concerned, but they have a similar arrowhead shape, so I'll give them an intermediate similarity rating." This notion must be supplemented with the idea that dimensions may not be included at all if there is no variation in them. For example, it does not even occur to some subjects to evaluate A and B on the basis of shape of arrowhead, and thus the subject might reason, "A and $B$ are far apart on orientation, so I'll give them a low similarity rating." Other properties that may be backgrounded in the comparison between A and B include vertical location of shape, thickness of lines, size, and movement (both A and B are stationary). Thus, the representation of Object A depends on its partner in comparison. The predicate "similar arrowhead shape" is applied to $A$ when it is compared with $C$ but perhaps not when it is compared with $\mathrm{B}$. The context sensitivity of representation can yield a nonmonotonic relation between shared features and similarity.

Another form of nonmonotonic judgment may arise from the way in which information is integrated. Anderson and Alexander (1971) found that adding moderately favorable information to highly favorable information

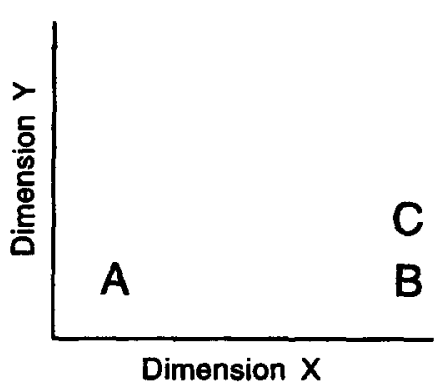

A

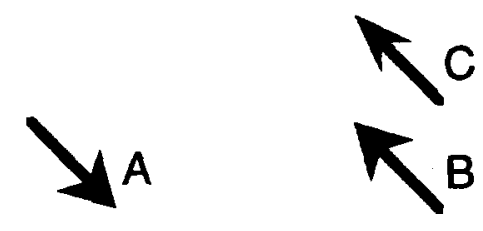

B

Figure 7. The top diagram shows an abstract situation in which nonmonotone similarity effects might be observed, and the stimuli in the lower diagram provide one concrete instantiation of this idea. 
produced less favorable responses. This result is not predicted by the rule that each piece of favorable information increases one's impression, but is predicted by the rule that one's impression is based on the average value of the incoming information. This result is problematic for any model that ascribes a single valence to a piece of information, since the same information can either increase or decrease one's overall impression (see also Birnbaum \& Mellers, 1983; Lopes, 1987).

Kahneman, Fredrickson, Schreiber, and Redelmeier (in press; see also Varey \& Kahneman, 1992) have recently found nonmonotonicities in people's ratings of discomfort. Participants were subjected to the painful experience of holding their hand in iced water for a period of time. The coldness level of the water could be varied between 1 (moderately painful) and 10 (extremely painful). Subjects rated the experience as more unpleasant if they received the coldness levels $\{2,5,8\}$ than they did if they received the levels $\{2,5,8,4\}$. That is, adding a moderately painful sample actually decreased unpleasantness judgments, as predicted by an averaging model.

Putting the above observations together raises some further puzzles. If two alternatives match on some feature, that feature may become backgrounded and have little influence. If they differ on a feature to some extent, so that that feature is foregrounded, just how that aspect influences judgment may depend on whether an averaging rule or an adding-integration rule is adopted, as well as on other information in the setting. Thus, for the example in Figure 7, if $\mathrm{B}$ and $\mathrm{C}$ were more similar in orientation, $A$ and $B$ might well have been rated as more similar than A and C.

\section{Justification and Judgment}

There is yet another critical way for situation representations to be constructed during judgment. The representation of a situation may be molded to fit a coherent explanation, or "story." A good deal of evidence in the decision-making literature indicates that people are biased to attend to information that fits their incipient account of a situation. In fact, nonexistent information may even be added to the description of a situation in order to have the description cohere with an explanation that has been developed.

Shafir and others (Shafir \& Tversky, 1992; Simonson, 1989; Tversky \& Shafir, 1992) have argued that people make judgments that they can justify by single, coherent reasons. When multiple, incoherent reasons justify a decision, people are less moved to action. For example, when students were given a choice of either planning to take a vacation or waiting to find out how well they did on an important exam before deciding on the vacation, students overwhelmingly chose to wait. However, the information actually had no influence on their judgments. Subjects who were told that they did poorly on the exam decided to take the vacation ("I need some consolation"), as did students who were told they did well on the exam ("I am rewarding myself"). According to Shafir and Tversky (1992), the explanation of why subjects want to wait for news of the exam result is that their reasons for taking the vacation are quite different depending on the result. Even though their end decision was identical whether they did poorly or well, subjects were biased to find a single coherent rationale for their decision.

In a similar vein, Kahneman and Tversky (1984) have shown that events that do not have compelling stories are judged to be less likely than events with such stories, even though the latter events are logically less likely. For example, subjects judge the probability of "a situation in which neither country intends to attack the other side with nuclear weapons, but an all-out nuclear war between the United States and Russia is triggered by the actions of a third country such as Iraq, Libya, Israel, or Pakistan" to be greater than "an all-out nuclear war between the United States and Russia" (Plous, 1993). Even though the latter situation logically subsumes the former, the former situation provides a concrete and compelling account of how a nuclear war might occur. A similar effect was also obtained when the less inclusive situation was described by a basic-level category label and the more inclusive situation was described by a superordinate category label (Bar-Hillel \& Neter, 1993). Carroll (1978) has shown that imagining an act in concrete detail (providing an account of how it came about) increases the subjective likelihood of the event.

Another line of evidence for a relation between justification and decision making comes from experiments that systematically manipulate whether subjects provide justifications for their decisions. Wilson and his colleagues report results from experiments in which some subjects were told to list the reasons for their decisions, while others simply focused on their feelings; subjects who had to justify or explain their judgments made objectively less satisfying choices (Wilson, Lisle, \& Craft, 1990) and displayed a lower attitude-behavior correlation (Wilson \& Dunn, 1986) than subjects who did not have to justify their choices (for a review, see Wilson, Dunn, Kraft, \& Lisle, 1989). These results may be interpreted as indicating that people's natural choices are not governed by justifications. However, the results also reveal that justifying a decision has a strong active role to play in the decision itself.

Although to our knowledge, no corresponding experiments have been conducted in the domain of similarity judgments, work in similarity does nonetheless seem also to be consistent with this "justifications" perspective. The previously discussed max effect (Goldstone et al., 1991) indicates that compared objects are given a higher similarity rating when a single unifying account can be provided for their likeness. Two abstract commonalities, or two superficial commonalities, increased similarity more than one abstract and one superficial commonality. Medin et al. (1993) showed that ambiguous items are interpreted in a manner that increases their similarity to compared items, as would be expected if subjects are trying to confirm an account that makes the items similar. In Sjöberg's (1972) words, "rating simi- 
larity may be construed sometimes as a problem solving task. There may be a cognitive set towards finding the similarity or, in other words, a tendency to justify as high a rating of similarity as possible" (p. 20). It is not surprising, then, that equivalents of confirmation biases are observed in similarity ratings.

\section{Summary of Constructive Processes}

Although computational models for similarity comparisons have begun to appear (e.g., Falkenhainer et al., 1989; Goldstone, 1994b; Holyoak \& Thagard, 1989), it is clear that we are not ready to offer a detailed process model that encompasses both similarity judgments and decision making. At the same time, however, we believe that we have shown that similarity making and decision making share subprocesses at a fairly specific level. They share, for instance, not only weighting of dimensions in the abstract but also compatibility, max, and justification-based weighting, and not only alignment in the abstract but also differential weighting of alignable and nonalignable differences. These correspondences encourage a further speculation, which we turn to before summing up.

\section{STANDARDS AND WEALS}

We began this paper by pointing out that decision making would seem more comparable to similarity judgments if one assumed that in decision making, an explicit or constructed ideal is present (see also Coombs \& Avrunin, 1988; E. E. Smith \& Osherson, 1989). This ideal might act like the target or standard in similarity comparisons. The parallel phenomena that we have reviewed suggest that this idea should be considered more seriously.

\section{Matching Standards and Weighting}

It is possible that similarity judgments and decision making do not simply share underlying processes, but are comparable in a deeper sense. In choice contexts, people may construct an ideal and then judge the similarity of the alternatives to that ideal, selecting the item that is closest (see Kahneman \& Miller, 1986, for related ideas on constructive processes in judgment). This view of decision making has many attractive features. On the one hand, there is some evidence that similarity comparisons are made in relation to some implied or constructed contrast set, while on the other, some studies suggest that decisions might be made in relation to some ideal.

\section{Certainty}

Consider a choice between receiving $\$ 2,400$ for sure versus a $66 \%$ chance of $\$ 2,400$, a $33 \%$ chance of $\$ 2,500$, and a $1 \%$ chance of nothing. The vast majority of people prefer the certain $\$ 2,400$. If, however, both options are reduced equally to produce a $34 \%$ chance of $\$ 2,400$ and a $66 \%$ chance of nothing versus a $33 \%$ chance of
$\$ 2,500$ and a $67 \%$ chance of nothing, the majority of people switch to the latter alternative. This has been interpreted by Kahneman and Tversky (1979) as a certainty effect, whereby people tend to overweight sure gains. Another way of interpreting this finding is that sure gains represent a match to an ideal, while near certainty does not.

\section{Coincidence}

There is converging evidence that identities on dimensional comparisons receive extra weight in similarity comparisons. To account for developmental changes in similarity judgments, L. B. Smith (1989) has advanced a model in which the major developmental change is an increased weighting of dimensional identities. Another finding that can be interpreted in terms of extra weighting of identity is the coincidence effect obtained by Gati and Tversky (1982). Considering Items $\mathrm{A}, \mathrm{C}$, and $\mathrm{E}$ in Figure 8, subjects generally find Items $\mathrm{A}$ and $\mathrm{E}$ to be more similar than Item $\mathrm{C}$ to the standard $\mathrm{T}$, even though in dimensional terms, $\mathrm{C}$ is closer to the target than either $\mathrm{A}$ or $\mathrm{E}$. The assumption is that since the diagonal alternative does not match the standard on either dimension, but the two other alternatives match the standard exactly on one of the dimensions, the matching dimension is given extra weight in these judgments.

Slovic et al. (1982) described a related effect. A hypothetical vaccine that reduces the probability of contracting a disease from 20 to $10 \%$ was less attractive if it was described as effective in half of the cases than if it was presented as fully effective against one of two mutually exclusive and equally probable virus strains that produce identical symptoms. Although the two scenarios are functionally equivalent, the scenario with two virus strains matches an ideal-namely, certain eradication of one type of virus.

This discussion naturally leads to the speculation that matches to some ideal on dimensions other than probability may also be disproportionately weighted in choice contexts. In the case of amounts, it may seem that the ideal is some infinite maximum, but one could describe

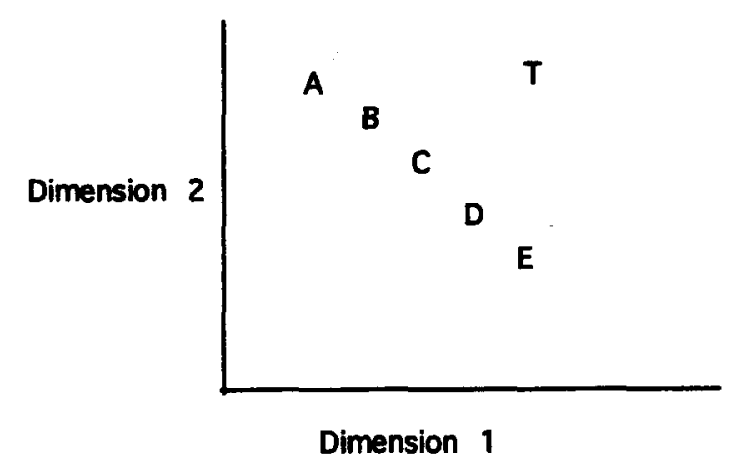

Figure 8. Paradigm for studying coincidence and compromise effects in similarity judgments. $T$ is the standard and either $A, C$, and $E$ or $B, C$, and $D$ are alternatives. Alternative $A$ matches or coincides with $\mathbf{T}$ on Dimension 2 and Alternative $\mathbf{E}$ matches $\mathbf{T}$ on Dimension 1. 
a situation where a person thinks that a salary of $x$ thousand dollars is ideal because to want more would be greedy but to get less would be insufficient. In addition, there are situations in which the absence of a value represents an ideal [e.g., the ideal diet food has 0 calories (Barsalou, 1983)]. Finally, there are situations in which a threshold value on a dimension may be important (e.g., a minimum requirement of 3 years experience to be considered for a job). If the certainty effect represents a disproportionate weighting of values that match an ideal on some dimension, the effect should generalize to other dimensions. In support of this idea, Lopes $(1981,1987)$ has pointed out that satisfying goals or aspiration levels can lead to violations of the axioms of expected-utility theory. For example, if John needs $\$ 40$ to take a bus home, he may prefer an alternative with an $80 \%$ chance of winning $\$ 50$ to one with a $70 \%$ chance of winning $\$ 100$ because the former alternative will maximize the probability of his satisfying his goal. 2 These examples suggest that, in both similarity judgments and decision making, ideal values and exact matches are emphasized.

\section{Compromise Revisited}

Coincidence effects do not appear to be especially compatible with the compromise effects discussed earlier. Note, however, that Gati and Tversky (1982) also included comparisons corresponding to B and D in Figure 8. Their results provide no evidence that $C$ was rated as more dissimilar than B or D to T. We would expect compromise effects to be stronger when they do not have to compete with coincidence effects.

The fact that coincidence effects appear to be obtained only when the (extreme) alternatives match the standard on a dimension has potential application in decision-making contexts. One could construct situations in which an ideal value on a dimension could be specified, creating a choice set analogous to A, C, and E relative to $\mathrm{T}$ in Figure 8. Under these conditions, a compromise effect might be much more difficult to obtain.

\footnotetext{
Alignability and Ideals

Other compatible evidence comes from a study by Houston, Sherman, and Baker (1991), who found that the distribution of positive and negative features in examples influences choice satisfaction. Their subjects' choices either shared good features and had unique bad features or shared bad features and had unique good features. Choice satisfaction and decision speed were greater when choices had unique good features and shared bad features. When choices have unique bad features, subjects may examine either option and see many reasons to reject it and no reasons to prefer it over the other choice. They may construct either an ideal that has all of the shared good features of the choices or an antiideal that has all of the shared bad features of the choices. A choice that offers an improvement over the anti-ideal is looked upon favorably. A choice that is worse than the ideal is unpopular because it suffers from being compared with the ideal.
}

Related work has been done in an analysis of decision making in legal trials. Pennington and Hastie (1986) suggest that integrated explanations of events, rather than assemblies of isolated facts, are likely to influence jurors. The definitions of relevant attributes (e.g., malicious state of mind) may act as a standard, and specific information in summaries is evaluated with respect to whether it instantiates the relevant attributes. Rather than relying on a summing of evidence, jurors appear to be evaluating information relative to a standard.

\section{Constructed Ideals}

In a situation in which the similarity of two graduate students is being evaluated, the contrast set may consist of other graduate students, and this set may determine the properties that are considered to be relevant to the comparison. The ideal then might be either the best prior example or a "super-example" compiled from the best qualities of the various examples. In decision making, the most radical example of a contextually derived contrast set comes from Brickman and Campbell's (1971) notion of a "hedonic treadmill," whereby rapid adaptation will cause the effects of any objective improvement to be short-lived. Once the improvement is in place, it acts as the "baseline" according to which other scenarios are evaluated. In situations that follow the course of a hedonic treadmill, the ideal is not a fixed entity, but, rather, is constantly being revised.

The idea that decisions involve comparisons with ideals is compatible with Simon's (1957) concept of an "aspiration level." Rather than choosing the option that maximizes our outcome, Simon argues, we often choose the choice that meets a certain aspiration level. Our suggested modification of this notion is that the aspiration level may not be a permanent fixed criterion, but may vary depending on contextual factors. We think this conjecture has at least one testable consequence-that adding an option to a choice set can decrease satisfaction and perhaps even lead to a rejection of all alternatives that would have been acceptable in a reduced-choice set. This counterintuitive prediction should occur when the added alternative has a very positive, novel feature but also negative offsetting features. If the novel positive feature becomes part of the constructed ideal, each of the alternatives should become less attractive (i.e., more distant from the ideal). We know of no test of this idea, though image theory (e.g., Beach \& Mitchell, 1987) seems compatible with it. According to image theory, alternatives may be evaluated in a noncompensatory manner in an early stage of processing to see if they are attractive enough to merit further consideration. It remains to be seen whether corresponding phenomena hold for similarity judgments; the evidence for constructive processes in similarity processing suggests that they might.

\section{CONCLUSIONS}

Rather than simply enumerating correspondences between similarity judgments and decision making, we 
have argued that the parallels discussed here strongly suggest common mental processes. By focusing on processes, we are departing from models in these domains that simply provide descriptive accounts of judgment behaviors. The shared processes should not be understood either as stages or as independent modules. The processes cannot be separated into distinct stages because they often depend upon each other; for example, the alignment of two items' properties is influenced not only by the weights associated with various properties, but also by the alignment process, which alters these weights. Similarly, the processes may not be subserved by special-purpose modules, because the same process that generates ideal points for comparisons may also, as a side effect, create new object properties.

We can return to our teaching-résumé example to see how these processes are invoked for similarity comparisons and merit decisions. For either type of judgment involving the applicants, the following processes are carried out: Properties of each applicant are weighted as a function of the applicant's other properties, the other applicant's description, and the method used to probe the judgment. For pairwise comparisons the descriptions of the two applicants are placed in alignment with each other; properties from other actual or ideal applicants are generated and applied to the compared applicants; new descriptions for the applicants are generated; evidence from the separate properties is integrated; and justification is sought for the overall impression of similarity or merit.

We prefer to think of this discussion as the beginning of the story rather than the end. There seem to be clear correspondences between similarity judgments and decision making. Critics may argue that we have given insufficient attention to differences between the two domains, and no doubt we are guilty of focusing on their alignable attributes and relations. Therefore, like George Miller (1956), we should withhold judgment as to whether these parallels are deep and profound. Nevertheless, in our opinion, they are provocative.

It is certainly not news that the similarity of choices affects decision making. But that is not the point of even the weakest form of our thesis. Our claim is that, in certain respects, similarity is more like a verb than a noun, more like an action than a state of affairs. At the level of action, we see extended parallels between similarity processing and decision making. Similarity processing and decision making display similar behaviors: Both involve an alignment process whereby the aspects of items are brought into correspondence with each other; both involve the active creation of new aspects, depending on the context and items being compared; both involve a justification and explanation process that can alter the course of the comparison or choice; and both may involve a comparison with ideals. The success of these principles for explaining the diverse phenomena in these two domains is an empirical question, but we believe that the commonalities provide grounds for optimism.

At the risk of fatuous self-reference, the claims that we have made about comparison making can be applied to the specific comparison between similarity and decision making. In particular, several cases of creating new aspects (comparison-dependent reinterpretation) have been suggested, wherein familiar phenomena in decision making have been cast in a different light by being compared with similarity judgments (and vice versa). The coincidence effect in similarity judgments can be seen as a special case of judgments based on ideal values. Negative attraction effects can be seen as a species of the diagnosticity effect found in similarity judgments. Mental-accounting and additive-difference models can be seen as instances of a general strategy of aligning alternatives before comparing them. In general, we do not suggest that the presence of a comparison process that is common to both domains implies that decision making can be reduced in some way to a similarity judgment (or vice versa). Indeed, the importance of context of judgment, justification of choice, and construction of aspects is an indication that for both similarity and choice, quite a bit of work remains to be done even after the correspondences have been determined, in much the same way as we have done here.

\section{REFERENCES}

AAKERS, J. (1991). The negative attraction effect? A study of the attraction effect under judgment and choice. Advances in Consumer Research, 18, 462-469.

Anderson, N. H., \& Alexander, G. R. (1971). Choice test of the averaging hypothesis for information integration. Cognitive Psychology, 2, 313-324.

ARrow, K. J. (1951). Social choice and individual values (Cowles Commission Monograph No. 12). New York: Wiley.

BAR-HILlel, M., \& NETER, E. (1993). How alike is it versus how likely is it: A disjunction fallacy in probability judgments. Journal of Personality \& Social Psychology, 65, 1119-1131.

Barsalou, L. W. (1983). Ad hoc categories. Memory \& Cognition, 11, 211-227.

Beach, L. R., \& Mitchell, T. R. (1987). Image theory: Principles, goals, and plans in decision making. Acta Psychologica, 66, 201-220.

Beike, D. R., \& Sherman, S. J. (1993, April). Status quo biases and loss aversion for undesirable items. Paper presented at the 65 th annual meeting of the American Psychological Association, Chicago, IL.

Birnbaum, M. H., \& Mellers, B. A. (1983). Bayesian inference: Combining base rates with opinions of sources who vary in credibility. Journal of Personality \& Social Psychology, 45, 792-804.

Brickman, P., \& Campbell, D. T. (1971). Hedonic relativism and planning the good society. In M. H. Appeley (Ed.), Adaptationlevel theory: $A$ symposium (pp. 287-302). New York: Academic Press.

Carroll, J. S. (1978). The effect of imagining an event on expectations for the event: An interpretation in terms of the availability heuristic. Journal of Experimental Social Psychology, 14, 88-96.

Clement, C. A., \& Gentner, D. (1991). Systematicity as a selection constraint in analogical mapping. Cognitive Science, 15, 89-132.

Coombs, C. H., \& Avrunin, G. S. (1988). The structure of conflict. Hillsdale, NJ: Erlbaum.

Falkenhainer, B., Forbus, K. D., \& Gentner, D. (1989). The structure mapping engine: Algorithm and examples. Artificial Intelligence, 41, 1-63.

Fillenbaum, S., \& RAPOPORT, A. (1974). Verbs of judging judged: A case study. Journal of Verbal Learning \& Verbal Behavior, 13, 54-62.

GATI, I., \& TVERSKY, A. (1982). Representations of qualitative and quantitative dimensions. Journal of Experimental Psychology: Human Perception \& Performance, 8, 325-340. 
GentNeR, D. (1983). Structure mapping: A theoretical framework for analogy. Cognitive Science, 7, 155-170.

GENTNER, D. (1989). The mechanisms of analogical learning. In S. Vosniadou \& A. Ortony (Eds.), Similarity, analogy, and thought (pp. 199-241). Cambridge: Cambridge University Press.

Gentner, D., \& Markman, A. B. (in press). Similarity is like analogy. In C. Cacciari (Ed.), Proceedings of the San Marino Workshop on Similarity. Milan: Bompiani.

GLuCKSBERG, S., \& KeYSAR, B. (1990). Understanding metaphorical comparisons: Beyond similarity. Psychological Review, 97, 3-18

Goldstone, R. L. (1993). Feature distribution and biased estimation of visual displays. Journal of Experimental Psychology: Human Perception \& Performance, 19, 564-579.

GoldSTONE, R. L. (1994a). The role of similarity in categorization Providing a groundwork. Cognition, 52, 125-157.

GoldStONE, R. L. (1994b). Similarity, interactive activation, and mapping. Journal of Experimental Psychology: Learning, Memory, \& Cognition, 20, 3-28.

Goldstone, R. L., Halberstadt, J., \& Medin, D. L. (1994). Non monotonicities in similarity judgements. Manuscript in preparation.

Goldstone, R. L., \& Medin, D. L. (1994a). Similarity, interactiveactivation and mapping. In K. J. Holyoak \& J. A. Barnden (Eds.) Advances in connectionist and neural computation theory: Vol. 2. Analogical connections (pp. 321-362). Norwood, NJ: Ablex.

Goldstone, R. L., \& Medin, D. L. (1994b). The time course of similarity. Journal of Experimental Psychology: Learning, Memory, \& Cognition, 20, 29-50.

Goldstone, R. L., Medin, D. L., \& Gentner, D. (1991). Relations attributes and the non-independence of features in similarity judgments. Cognitive Psychology, 23, 222-262.

Grether, D. M., \& PlotT, C. R. (1979). Economic theory of choice and the preference reversal phenomenon. American Economic Review, 69, 623-638.

Heath, T. B., \& ChatterJee, S. (1991). How entrants affect multiple brands: A dual attraction mechanism. Advances in Consumer Research, 18, 768-772.

Herr, P. M., Sherman, S. J., \& Fazio, R. H. (1983). On the consequences of priming: Assimilation and contrast effects. Journal of Experimental Social Psychology, 19, 323-340.

HoGARTH, R. M. (1980). Judgement and choice: The psychology of decision. London: Wiley.

Holyoak, K. J., \& THAGaRD, P. (1989). Analogical mapping by constraint satisfaction. Cognitive Science, 13, 295-355.

Houston, D. A., Sherman, S. J., \& Baker, S. M. (1989). The influence of unique features and direction of comparison on preferences. Journal of Experimental Social Psychology, 25, 121-141.

Houston, D. A., Sherman, S. J., \& Baker, S. M. (1991). Feature matching, unique features, and the dynamics of the choice process: Predecision conflict and postdecision satisfaction. Journal of Ex perimental Social Psychology, 27, 411-430.

Huber, J., Payne, J. W., \& Puto, C. (1982). Adding asymmetrically dominated alternatives: Violations of regularity and the similarity hypothesis. Journal of Consumer Research, 9, 90-98.

HubER, J., \& Puto, C. (1983). Market boundaries and product choice: Illustrating attraction and substitution effects. Journal of Consumer Research, 10, 31-44.

JAMES, W. (1989). Psychology: The briefer course. Notre Dame, IN: Notre Dame University Press. (Original work published 1892)

JoHNSON, M. D. (1984). Consumer choice strategies for comparing noncomparable alternatives. Journal of Consumer Research, 11, 741-753.

JoHnson, M. D. (1986). Modeling choice strategies for noncomparable alternatives. Marketing Science, 5, 37-54.

Johnson, M. D. (1989). The differential processing of product category and noncomparable choice alternatives. Journal of Consumer Research, 16, 300-309.

Kahneman, D., Fredrickson, B. L., Schreiber, C. A., \& RedelMEIER, D. A. (in press). When more pain is preferred to less: Adding a better end. Psychological Science.

Kahneman, D., Knetsch, J. L., \& Thaler, R. (1990). Experimental tests of the endowment effect and the coarse theorem. Journal of Political Economy, 98, 1325-1348.
Kahneman, D., \& Miller, D. T. (1986). Comparing reality to its alternatives. Psychological Review, 93, 136-153.

Kahneman, D., \& TVersky, A. (1979). Prospect theory: An analysis of decisions under uncertainty. Econometrica, 47, 263-291.

Kahneman, D., \& Tversky, A. (1984). Choices, values, and frames. American Psychologist, 39, 341-350.

Kitayama, S., Markus, H., Tummala, P., Kurokawa, M., \& Kato, K. (1990). Culture and self-cognition. Unpublished manuscript.

KNETSCH, J. L., \& SINDEN, J. A. (1984). Willingness to pay and compensation demanded: Experimental evidence of an unexpected disparity in measures of value. Quarterly Journal of Economics, 99, $507-521$.

Levin, I. P., Johnson, R. D., \& Faraone, S. V. (1984). Information integration in price-quality tradeoffs: The effect of missing information. Memory \& Cognition, 12, 96-102.

Lichtenstein, S., \& SLOVIC, P. (1973). Response induced reversals of preference in gambling: An extended replication in Las Vegas. Journal of Experimental Psychology, 101, 16-20.

LoEWENSTEIN, G. F. (1988). Frames of mind in temporal choice. Management Science, 34, 200-214.

LOPES, L. L. (1981). Decision making in the short run. Journal of Experimental Psychology: Human Learning \& Memory, 7, 377-385.

LOPES, L. L. (1987). Between hope and fear: The psychology of risk. Advances in Experimental Social Psychology, 20, 255-295.

LUCE, R. D. (1959). Individual choice behavior. New York: Wiley.

Markman, A. B., \& Gentner, D. (1993a). Splitting the differences: A structural alignment view of similarity. Joumal of Memory \& Language, 32, 517-535.

Markman, A. B., \& Gentner, D. (1993b). Structural alignment during similarity comparisons. Cognitive Psychology, 25, 431-467.

MarKus, H. R., \& Kitayama, S. (1991). Culture and the self: Implications for cognition, emotion, and motivation. Psychological Review, 98, 224-253

Medin, D. L., Goldstone, R. L., \& Gentner, D. (1993). Respects for similarity. Psychological Review, 100, 254-278.

MEdIN, D. L., \& KROLL, J. (1994). Studies of diagnosticity involving attributes and relations. Manuscript in preparation.

Medin, D. L., Pineda, K., \& Markman, A. M. (1994, May). Parallels between similarity making and decision making. Paper presented at the 66th annual meeting of the Midwestern Psychological Association, Chicago, IL.

Miller, G. A. (1956). The magical number seven plus or minus two: Some limits on our capacity for processing information. Psychological Review, 63, 81-97.

Montgomery, H. (1983). Decision rules and the search for a dominance structure: Towards a process model of decision making. In P. C. Humphreys, O. Svenson, \& A. Vari (Eds.), Analyzing and aiding decision processes (pp. 343-369). Amsterdam: North-Holland.

Murphy, G. L., \& MEDIN, D. L. (1985). The role of theories in conceptual coherence. Psychological Review, 92, 289-316.

PAYNE, J. W. (1976). Task complexity and contingent processing in decision making: An information search and protocol analysis. Organizational Behavior \& Human Performance, 16, 366-387.

PAYNE, J. W. (1982). Contingent decision behavior. Psychological Bulletin, 92, 382-402.

Payne, J. W., \& Bettman, J. R. (1992). Behavioral decision research: A constructive processing perspective. Annual Review of Psychology, 43, 87-131.

Pennington, N., \& Hastie, R. (1986). Evidence evaluation in complex decision making. Journal of Personality \& Social Psychology, 51, 242-258.

Plous, S. (1993). The psychology of judgment and decision making. New York: McGraw-Hill.

Ratneshwar, S., Shocker, A. D., \& Stewart, D. W. (1987). Toward understanding the attraction effect: The implications of product stimulus meaningfulness and familiarity. Journal of Consumer Research, 13, 520-533.

Restle, F. (1961). Psychology of judgment and choice. New York: Wiley.

Rosch, E. (1975). Cognitive reference points. Cognitive Psychology, 7, 532-547. 
RUBINSTEIN, A. (1988). Similarity and decision making under risk (Is there a utility theory resolution?). Journal of Economic Theory, 46, 145-153.

Russo, J. E., \& DOSHER, B. A. (1983). Strategies for multiattribute binary choice. Learning, Memory \& Cognition, 9, 676-696.

Sanbonmatsu, D. M., Kardes, F. R., \& Gibson, B. D. (1991). The role of attribute knowledge and overall evaluations in comparative judgment. Organizational Behavior \& Human Decision Processes, 48, 131-146.

ShafIR, E. (1992). Prospect theory and political analysis: A psychological perspective. Political Psychology, 13, 311-322.

SHAFIR, E. (1993). Choosing versus rejecting: Why some options are both better and worse than others. Memory \& Cognition, 21, 546-556.

Shafir, E., Osherson, D. N., \& Smith, E. E. (1993). The advantage model: A comparative theory of evaluation and choice under risk. Organizational Behavior \& Human Decision Processes, 55, 325-378.

ShaFIR, E., \& Tversky, A. (1992). Thinking through uncertainty: Nonconsequential reasoning and choice. Cognitive Psychology, 24, 449-474.

SHEPARD, R. N. (1962a). The analysis of proximities: Multidimensional scaling with an unknown distance function: Part I. Psychometrika, 27, 125-140.

ShEPARd, R. N. (1962b). The analysis of proximities: Multidimensional scaling with an unknown distance function: Part II. Psychometrika, 27, 219-246.

Simon, H. A. (1957). Models of man. New York: Wiley.

SimONSON, I. (1989). Choice based on reasons: The case of attraction on compromise effects. Journal of Consumer Research, 16, 158-174.

Simonson, I., \& TVersky, A. (1992). Choice in context: Tradeoff contrast and extremeness aversion. Journal of Marketing Research, 29, 281-295.

SJöBERG, L. (1972). A cognitive theory of similarity. Göteberg Psychological Reports, 2, 1-23.

SLOVIC, P. (1975). Choice between equally valued alternatives. Jour nal of Experimental Psychology: Human Perception \& Performance, 104, 280-287.

Slovic, P., Fischhoff, B., \& Lichtenstein, S. (1982). Response mode, framing, and information-processing effects in risk assessment. In R. Hogarth (Ed.), New directions for methodology of social and behavioral science: Question framing and response consistency (pp. 21-36). San Francisco: Jossey-Bass.

Slovic, P., \& MacPhillamy, D. (1974). Dimensional commensurability and cue utilization in comparative judgment. Organizational Behavior \& Human Performance, 11, 172-194.

SMith, E. E., \& OSherson, D. N. (1989). Similarity and decision making. In S. Vosniadou \& A. Ortony (Eds.), Similarity and analogical reasoning (pp. 60-75). Cambridge: Cambridge University Press.

SMITH, L. B. (1989). A model of perceptual classification in children and adults. Psychological Review, 96, 1-20.

Thaler, R. H. (1985). Mental accounting and consumer choice. Marketing Science, 4, 199-214.

TVERSKy, A. (1969). Intransitivity of preferences. Psychological Review, 76, 31-48.
TVERSKY, A. (1972). Elimination by aspects: A theory of choice. Psychological Review, 79, 281-299.

TVErSky, A. (1977). Features of similarity. Psychological Review, 84, 327-352.

TVersky, A., \& Gati, I. (1978). Studies of similarity. In E. Rosch \& B. Lloyd (Eds.), Cognition and categorization (pp. 79-98). Hillsdale, NJ: Erlbaum.

TVERSKY, A., \& GATI, I. (1982). Similarity, separability, and the triangle inequality. Psychological Review, 89, 123-154.

TVERSKY, A., \& KAHNEMAN, D. (1986). Rational choice and the framing of decisions. Journal of Business, 59, 25 1-278.

TVERSKY, A., \& KaHNEMAN, D. (1991). Loss aversion and riskless choice: A reference dependent model. Quarterly Journal of Economics, 107, 1039-1061.

Tversky, A., \& Sattath, S. (1979). Preference trees. Psychological Review, 86, 542-573.

TVersky, A., Sattath, S., \& Slovic, P. (1988). Contingent weighting in judgment and choice. Psychological Review, 95, 371-384.

TVersky, A., \& Shafir, E. (1992). The disjunction effect in choice under uncertainty. Psychological Science, 3, 305-309.

VAREY, C., \& KahNeman, D. (1992). Experiences extend across time: Evaluation of moments and episodes. Journal of Behavioral Decision Making, 5, 169-185.

Wilson, T. D., \& DunN, D. S. (1986). Effects of introspection on attitude-behavior consistency: Analyzing reasons versus focusing on feelings. Journal of Experimental Social Psychology, 22, 249-263.

Wilson, T. D., DunN, D., KRAFT, D., \& Lisle, D. J. (1989). Introspection, attitude change, and attitude behavior consistency: The disruptive effects of explaining why we feel the way we do. In L. Berkowitz (Ed.), Advances in experimental social psychology (Vol. 19, pp. 123-205). New York: Academic Press.

Wilson, T. D., Lisle, D. J., \& KRAFT, D. (1990). Effects of selfreflection on attitudes and consumer decision. Advances in Consumer Research, 17, 79-85.

YamaGishI, T., \& Hill, C. T. (1981). Adding versus averaging models revisited: A test of a path-analytic integration model. Journal of Personality \& Social Psychology, 41, 13-25.

\section{NOTES}

1. It may be possible to account for this type of ambiguity resolution within a structural-alignment model by allowing inferences to be made from one representation to the other (e.g., Gentner, 1989). See Clement and Gentner (1991) for a discussion of this inference process.

2. On the other side, Adelberg and Batson (1978) present some evidence suggesting that subjects underweight matches to an ideal in situations in which they have limited resources and must justify their decisions.

(Manuscript received November 12, 1993; revision accepted for publication June 23, 1994.) 